East African Medical Journal Vol. 87 No. 4 April 2010

MANAGEMENT OF DIABETIC KETOACIDOSIS IN CHILDREN AND ADOLESCENTS IN SUB-SAHARAN AFRICA: A REVIEW

E.S. Majaliwa, MD, Department of Paediatrics and Child Health, Muhimbili National Hospital, P.O. Box 65000, Dar es Salaam, Tanzania, Department of Paediatrics, University of Chieti, Via dei Vestini 5, 66100 Chieti, Italy, A. Mohn, MD, V. Chiavaroli, MD, Department of Paediatrics, University of Chieti, Via dei Vestini 5, 66100 Chieti, Italy, K. Ramaiya, MMed, Department of Internal Medicine, Hindu Mandal Hospital, Dar es Salaam, Tanzania, A.B.M. Swai, PhD, Department of Internal Medicine, Muhimbili National Hospital, P.O. Box 65000, Dar es Salaam, Tanzania and F. Chiarelli, PhD, Department of Paediatrics, University of Chieti, Via dei Vestini 5, 66100 Chieti, Italy

Request for reprints to: Dr. E. S. Majaliwa, Department of Paediatrics and Child Health, Muhimbili National Hospital, P.O. Box 65000, Dar es Salaam, Tanzania

\title{
MANAGEMENT OF DIABETIC KETOACIDOSIS IN CHILDREN AND ADOLESCENTS IN SUB-SAHARAN AFRICA: A REVIEW
}

\author{
E.S. MAJALIWA, A. MOHN, V. CHIAVAROLI, K. RAMAIYA, A.B.M. SWAI and F. CHIARELLI
}

\begin{abstract}
Background:Diabetic ketoacidosis (DKA) is a complex metabolic state of hyperglycaemia, ketosis, and acidosis. Diabetes in sub-Saharan Africa is, in many patients a serious disease with a poor prognosis. Most deaths, however, are due to preventable causes.

Objective: To improve knowledge on the management of DKA in sub-Saharan Africa. Data sources: Literature review from different published sources.

Data synthesis: Health systems in sub-Saharan Africa are currently organised for the treatment of episodes of illness and not long-term conditions like diabetes. Therefore the high rates of DKA is essentially due to lack of training of health professionals, lack of facilities in most hospitals, lack of public awareness as well as lack of health education to individual patients/families. In addition erratic insulin supply coupling with infections, low parental education, poor insulin storage and lack of facilities for self monitoring of blood glucose.

Conclusion: A complex unfavourable social and economic environment is the basis of the high prevalence of DKA in sub-Saharan Africa. Several episodes of DKA can be prevented by effective public awareness programmes and education to healthcare providers.
\end{abstract}

\section{INTRODUCTION}

Diabetic ketoacidosis (DKA) has been recognised as the main complication and potentially fatal emergency in children and adolescents with type 1 diabetes mellitus (T1DM) (1). Definition of DKA includes hyperglycaemia (blood glucose $>11 \mathrm{mmol} /$ $\mathrm{L}[\sim 200 \mathrm{mg} / \mathrm{dL}]$ ), venous $\mathrm{pH}<7.3$ or bicarbonate $<15$ $\mathrm{mmol} / \mathrm{L}$, in association with ketonemia, ketonuria and glycosuria; occasionally some patients present with normal glycaemic ketoacidosis (2). A decrease in serum insulin and a glucoregulatory hormones imbalance, causing hyperglycaemia, lipolysis and acidosis, are responsible for developing DKA (1). DKA occurs all over the world with reported frequency rates higher in developing countries than in the industrialised world. Frequencies of DKA range from 15 to $70 \%$ in Europe, Australia and North America (3-5). The prevalence rate of diabetes continues to grow in all Western nations (6), however the prevalence of DKA has remained low, principally following prevention programmes (7). In developing countries, specifically sub-Saharan
Africa very little primary data exist on T1DM and most information depends on anecdote. The few data available estimate the incidence to be $1.5 / 100,000$ in Tanzania (8), an increase in incidence from 9.5/100,000 in 1991 to $10.3 / 100,000$ in 1995 in Sudan (9), with the prevalence of DKA ranging between 42 to $76 \%(10,11)$.

Mosthealthcare workers are not able to recognise symptoms and signs of DKA in sub-Saharan Africa, which contributes tohigh rates of DKA at presentation (12). In fact the report by International Insulin Foundation in three African countries, found that many doctors were scared of insulin and diabetes, and the only training on diabetes they have ever had was during their university education (13). In contrast it was found that the same health workers were able to recognise all other common diseases in their setting with the resources they have, reflecting the little importance given to diabetes.

DKA at diagnosis is more common in younger children $(<5$ years of age) and in children whose families do not have readily access to medical care for social or economic reasons (14), lower income and 
lack of healthinsurance (15). Prevalence of DKAat the time of diagnosis in sub-Saharan Africa was found to be between 70 to $80 \%(13,14)$. Due to lack of health care workers training and facilities for diagnosis, many children might be misdiagnosed as malaria or meningitis in a busy emergency department of many hospitals in sub-Saharan Africa (16).

DKA after diagnosis in western countries is in the range of 16 to $36 \%$ (6), in contrast to the rates in Africa which are as high as $76 \%$ (11). These high rates are attributable to erratic insulin supply coupling with infections $(11,14,17)$, low parental education, poor insulin storage as well as lack of facilities for blood glucose monitoring.

The mortality due to DKA in Europe is well below $5 \%(18,19)$ yet in sub-Saharan Africa there has been no reported reduction in mortality rates, stressing further the importance of diabetes awareness, reliable insulin supply and availability of glucose monitoring facilities, both in hospitals and to individual patients.

Strategies areessential for prediction, prevention and successful treatment of DKA in infants, children, and adolescents. Therefore, strategies for management of DKA and its complications in children and adolescents with T1DM are essential. Since there is very little known on T1DM in sub-Saharan Africa this paper aims to review the main aspects of the management and prevention of DKA in children and adolescents in sub-Saharan Africa.

\section{PATHOPHYSIOLOGY OF DKA}

Several metabolic alterations are responsible for developing DKA. The primary cause is insulin deficiency, which may be precipitated by infection or other forms of stress. The subsequent increase of glucoregulatory hormones leads to an increased hepatic glyconeogenesis and glycogenolysis leading to an high release of glucose, as well as proteins and fat from muscle and adipose tissues. These metabolicevents lead to increased lipolysis and ketone production with the end result of hyperglycaemia, ketonemia, increased plasma osmolarity and kidney glycaemic load. As hyperglycaemia exceeds the renal threshold, it leads to osmotic diuresis, electrolyte loss, and eventually dehydration. The subsequent reduced kidney function is responsible for retention of glucose and increased plasma anion gap.

DKA is generally categorised by the severity of the acidosis, varying from mild DKA (venous $\mathrm{pH}$ : $<7.30$ and / or bicarbonate concentration $<15 \mathrm{mmol} /$ L), moderate DKA ( $\mathrm{pH}:<7.2$ and/or bicarbonate: $<10 \mathrm{mmol} / \mathrm{L}$ ) to severe DKA ( $\mathrm{pH}:<7.1$, and/or bicarbonate: $<5 \mathrm{mmol} / \mathrm{L})(2,20)$.

\section{MANAGEMENT STRATEGIES}

Management of DKAneeds to be prompt and helpful to correct metabolic abnormalities. One should identify and treat the precipitating factors and comorbid conditions, set appropriate longterm plan to prevent recurrence and intend to maintain adequate diabetes control. The therapeutic goals consist of replacement of insulin to lower hyperglycaemia and reverse ketogenesis, fluid and electrolyte replacement to correct dehydration and metabolic acidosis and management of precipitating or co-morbid conditions. It is necessary to perform a complete and meticolous physical evaluation to establish gravity of patient's status and its underlying pathogenesis (major components are insulinopenia, infection or physiological stress) (Tables 1 and 2).

Table 1

Patients preliminary assessment and monitoring
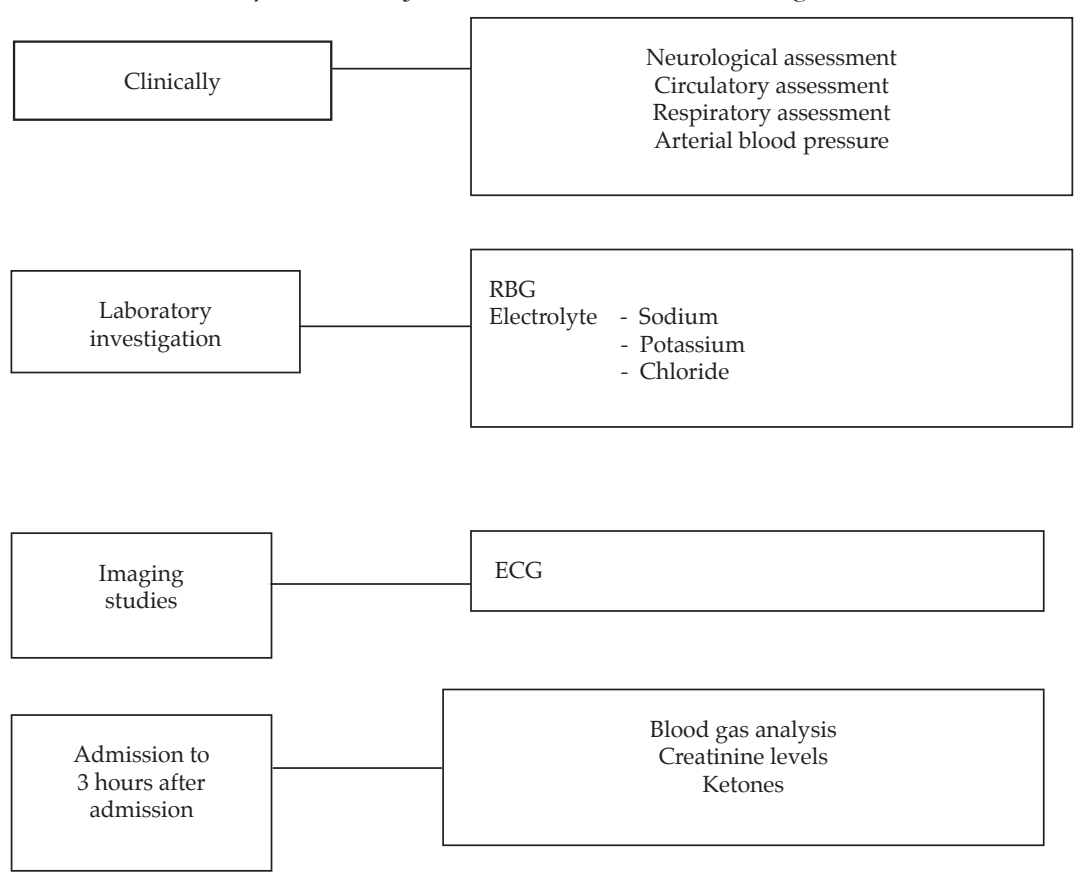
Table 2

Assessment of dehydration status (21)

\begin{tabular}{lccc}
\hline & Mild & Moderate & Severe \\
\hline$\%$ weight & $3-5$ & $5-9$ & 10 \\
$\mathrm{Mg} / \mathrm{kg}$ & $30-50$ & $50-90$ & 100 \\
Heart rate & $\mathrm{N}$ & $\boldsymbol{\downarrow}$ & $\boldsymbol{4}$ \\
Blood pressure & $\mathrm{N}$ & $\boldsymbol{\nabla}$ \\
Behaviour & $\mathrm{N}$ & Irritable & Lethargic \\
Mucous membrane & $\mathrm{N}$ & Dry & Very dry \\
Tears & Present & $\boldsymbol{\nabla}$ & Absent \\
Skin tugor & $\mathrm{N}$ & & Cold cyanotic \\
\hline
\end{tabular}

$\mathrm{N}=$ Normal, $\boldsymbol{\downarrow}=$ Reduced, $\boldsymbol{\Lambda}=$ Increased

Treatment consists primarily of insulin administration and replacement of fluid and electrolytes (Table 3). Likewise prevention hinges on avoiding insulin deficiency by regularuse of insulin for control of glucose and compensation for stress. Because of the metabolic derangements of DKA, some laboratory tests can be misleading and need to be carefully interpreted.

Since in sub-Saharan Africa one of the most common causes of DKA is infections like pneumonia, malaria, UTI and tuberculosis, screening for infections should be done (1).

\section{TREATMENT}

Assessment of the clinical status of the child, laboratory investigations and electrographic monitoring need to be regularly performed: hourly or more frequently if required (Tables 1 and 2). However fluid input and output should be assessed.

Fluid and electrolyte therapy: The first measure towards restoration of fluid and electrolyte deficit is to start venous infusion on the basis of estimated dehydration level (Table 3). (i) Initially normal saline $(0.9 \% \mathrm{Nacl})$ or Ringer's lactate.

(ii) Use of colloids is not necessary.

(iii) Later, a hypotonic solution should be provided $(0.45 \% \mathrm{NaCl})$ to avoid excessive increase of serum sodium concentration.

(iv) Amount of fluid must be given evenly over 48 hours, (21)

(v) The most recommended formulas to obtain the corrected sodium are: measured $\mathrm{Na}+2$ $x[($ glucose $\mathrm{mmol} / 1$ - 5.6) / 5.6] or $\mathrm{Na}+2 \mathrm{x}$ [(glucose mg/dl - 100) / 100]. As known, serum electrolytes, determination of osmolality and anion gap could be helpful to assess doses and duration of fluid and electrolyte therapy.

(vi) Oral fluids should be started when the patient feels good, the clinical condition is getting better and the patient is able to drink.

(vii) Oral fluid volume should be subtracted from intravenous intake.

Insulin

(i) After beginning initial rehydration, intravenous insulin infusion is fundamental in order to restore homeostasis and stop further ketone production.

Table 3

Fluid and electrolyte (21)

\begin{tabular}{llll}
\hline Weight & $0-10 \mathrm{~kg}$ & $10.1-20 \mathrm{~kg}$ & $>20 \mathrm{~kg}$ \\
Fluid & $100 \mathrm{ml} / \mathrm{kg}$ & $\begin{array}{l}1000 \mathrm{ml}+50 \mathrm{ml} / \mathrm{kg} \\
\text { per every kg }>10 \mathrm{~kg}\end{array}$ & $\begin{array}{l}1500 \mathrm{ml}+20 \mathrm{ml} \\
\text { per every kg }>20 \mathrm{~kg}\end{array}$ \\
Sodium & $3 \mathrm{mEq} / \mathrm{kg}$ & $3 \mathrm{mEq} / \mathrm{kg}$ & $3 \mathrm{mEq} / \mathrm{kg}$ \\
Potassium & $2 \mathrm{mEq} / \mathrm{kg}$ & $2 \mathrm{mEq} / \mathrm{kg}$ & $2 \mathrm{mEq} / \mathrm{kg}$ \\
Chloride & $5 \mathrm{mEq} / \mathrm{kg}$ & $5 \mathrm{mEq} / \mathrm{kg}$ & $5 \mathrm{mEq} / \mathrm{kg}$ \\
\hline
\end{tabular}


(ii) If the patient is in shock it is not indicated to start insulin until resolved

(iii) In other cases, insulin should be started 1-2 hours after beginning rehydration (22) at a dose of 0.1 unit $/ \mathrm{kg} /$ hour (some recommend 0.05 units $/ \mathrm{kg} /$ hour particularly for younger patients $<10 \mathrm{~kg}$ ). This dose should reduce glycaemia and continued until correction of acidosis (23).

(iv) If blood glucose is decreasing too fast the dose of insulin should be reduced to $0.05 \mathrm{U} / \mathrm{kg} / \mathrm{hour}$.

(v) When the blood glucose is between 14-17 $\mathrm{mmol} / 1$ insulin rate should be dropped by half and change the infusion to saline solution' and added glucose.

(vi) Whensyringe pumps for insulinarenotavailable a separate low-dose infusion may be given, as soluble insulin 50 units in $500 \mathrm{ml}$ normal saline solution at a dose of $0.1 \mathrm{unit} / \mathrm{kg} / \mathrm{hr}$ (24).

(vii) Whenitis notpossibletoperforminfusion, hourly $1 \mathrm{M}$ injections of soluble or rapid-acting insulin 0.1 units $/ \mathrm{kg}$ has been used helpfully (25).

(viii) Subcutaneous insulin should be started when ketoacidosis has resolved, the patient is well hydrated and patient can eat: the best approach is changing to subcutaneous insulin before a meal.

(ix) Subsequently, continue to monitor glycaemia levels on regular basis and titrate insulin dose with glucose levels.

In circumstances where intravenous administration is not possible and in a patient with uncomplicated DKA, hourly or after two hours intramuscular administration of short or rapid acting insulin analogs (Insulin lispro or insulin aspart) have been used effectively (26). This regimen can be used in ambulatory patients where hospitalisation is costly.

Potassium: Reduced potassium is a common feature of ketoacidosis, related to prolonged duration of evolution of DKA, deficit of 3 to $6 \mathrm{mmol} / \mathrm{kg}$ (27). It is unusual to find normal or high potassium at the time of presentation due to the passage of intracellular potassium into the intravascular space masking the actual reduction of the electrolyte. After starting insulin therapy and improvement of acidosis, there is a progressive return of potassium into the cells causing hypokalaemia. If serum potassium is not available before the completion of resuscitation, ECG monitoring is recommended before potassium is added to infusion fluid. Flattening of the wave, widening of the QT interval, and the appearance of $\mathrm{U}$ waves indicate hypokalaemia, while tall, peaked, symmetrical $\mathrm{T}$ waves and shortening of the QT interval are signs of hyperkalaemia.

(i) In hypokalaemic patients, potassium administration as slow infusion should start immediately, before initiation of insulin therapy. (ii) In normokalaemic patients, potassium replacement is recommended after the first or second hour of treatment.

(iii) In hyperkalaemic patients, potassium replacement is delayed until urine output is documented.

(iv) The dose of potassium (KCL) is $4-10 \mathrm{mmol} / \mathrm{hr}$ in the initial infusion and continues throughout the parenteral infusion (the maximum recommended rate of intravenous potassium replacement is usually $0.5 \mathrm{mmol} / \mathrm{kg} /$ hour). Overzealous potassium replacement should be avoided where monitoring is not close.

Sodium: If serum osmolality fails to rise, and particularly if it falls, careful re-evaluation of fluid replacement is required. Consideration to increase the concentration of sodium chloride is important at this point, however increased vigilance for signs of cerebral oedema is extremely important. The physiological saline will correct the sodium deficit, however:

(i) if the serum sodium is $<140 \mathrm{mEq} / 1: 0.9 \% \mathrm{NaCI}$ should be used.

(ii) if the serum sodium is $>140 \mathrm{mEq} / 1$ : $0.45 \% \mathrm{NaCI}$ should be used.

Phosphate:Adversecomplications ofhypophosphatemia are uncommon and occur primarily in patients with severe hypophosphatemia [a serum phosphate concentration of less than $1.0 \mathrm{mg}$ per dL $(0.32$ mmol per L)] (28). There is no clinical benefit for phosphate replacement in the treatment of DKA, and excessive phosphate replacement may contribute to hypocalcaemia and soft tissue calcification (29).

Acidosis and sodium bicarbonate replacement: Usually severe acidosis is reversed by fluid and insulin replacement. Insulin stops further ketones production and allows ketoacids to be metabolised, which generates bicarbonate.

By treating hypovolaemia, tissue perfusion is improved hence improvement of renal function with consequent increase in excretion of organic acids. Regarding use of sodium bicarbonate, there are exceptional cases where there is a clear indication to perform bicarbonate infusion. Nevertheless, there may be selected patients who may benefit from bicarbonate therapy. These include patients with severe acidemia (arterial $\mathrm{pH}<6.9$ ) (30), and those with life-threatening hyperkalaemia. Cautious administration of $1-2 \mathrm{mmol} / \mathrm{kg}$ over $60 \mathrm{~min}$ may suffice.

To monitor carefully DKA progress and its management, it can be helpful to use the following diary (Figure 1). 
Figure 1

DKA monitoring chart

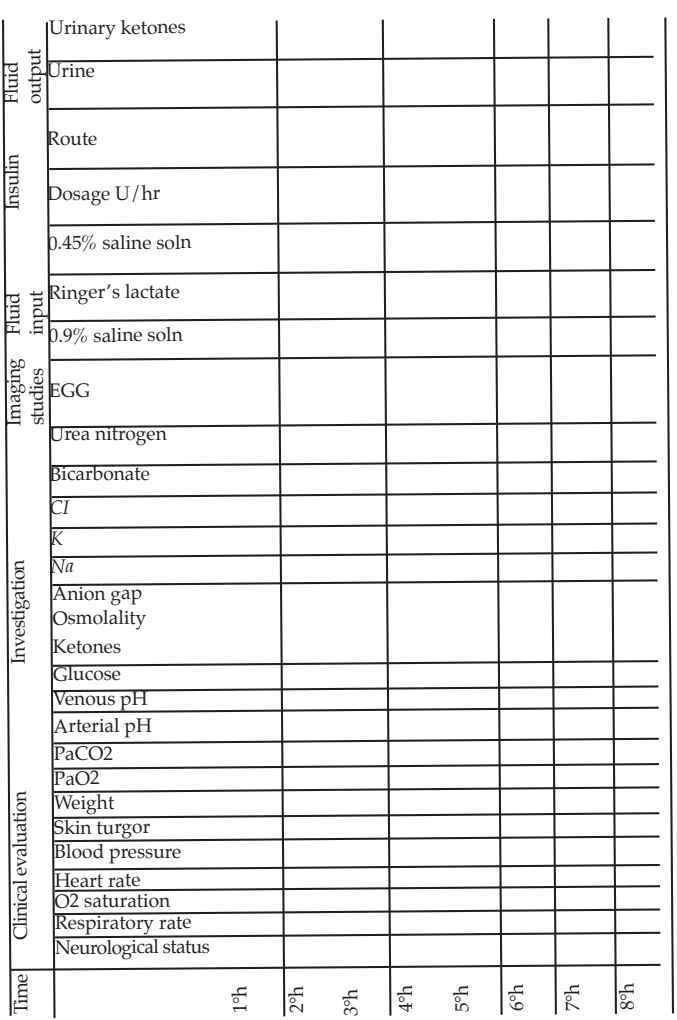

\section{COMPLICATIONS}

Cerebral oedema: Cerebral oedema is one of the most dreadful complications of DKA in children that require a prompt recognition to reduce related mortality or irreversible neurological damages. Mortality estimates vary widely, but some authors suggest that the disorder is lethal in about 20 to $50 \%$ of patients, particularly children (31). Fortunately, it is a rare occurrence, complicating about 0.5 to $0.9 \%$ of cases of DKA (32).
The pathogenesis of this complication may be complex. A number of mechanisms have been proposed including the role of cerebral ischaemia / hypoxia and the generation of various inflammatory mediators $(33,34)$, increased cerebral blood flow (35), disruption of cell membrane ion transport (36) and aquaporin channels (37). The generation of intracellular organic osmolytes (myoinsoitol, taurine) and subsequent cellular osmotic imbalance have also been implicated (38). Furthermore, high glycaemia and serum sodium levels cause contraction of cell volume due to a fluid shift from the intracellular to the extracellular compartment. By starting therapy, decline in serum osmolality reverses this mechanism with rapid expansion of cerebral intracellular volume causing successive cell swelling and raised intracranial pressure (21).

Typically, symptomatic cerebral oedema occurs 4-12 hours after the initiation of therapy but cases have also occurred before initiation of therapy (39) and as late as 24-28 hours after the initiation of treatment (40) (Table 4).

Management of cerebral oedema:

(i) Intravenous mannitol should be given at the dose of $0.25-1.0 \mathrm{~g} / \mathrm{kg}$ over 20 minutes; repeating the infusion if there is no response within two hours.

(ii) Anhypertonic saline solution (3\%) at the dose of $5-10 \mathrm{ml} / \mathrm{kg}$ over 30 minutes, can be used instead of mannitol (40).

(iii) Elevation of the patient's head is necessary to favour venous blood return and reduce intracranial pressure.

(iv) Intubation and ventilation may be necessary.

Other complications of DKA are summarised below (Table 5):

Table 4

Signs and symptoms of cerebral oedema $(21,31)$

Risk factors for cerebral oedema

- Age $<5$ years due to immaturity of autoregulatory systems

- Children with newly diagnosed T1DM

- Prolonged duration of metabolic derangements

- Severe acidosis and low pCO2

- Failure of sodium ions to rise as predicted
Signs and symptoms of cerebral oedema

- Sudden onset of headache

- Vomiting, blurring of vision

- Bradycardia postural hypotension

- Circulatory compromise

- Respiratory failure

- Decreased level of consciousness

- Papilloedema seizures and coma 
Table 5

Other complications of DKA

Pulmonary complications (oedema, aspiration pneumonia,)

\begin{tabular}{ll}
\hline $\begin{array}{l}\text { Hypokalaemia or } \\
\text { hyperkalaemia }\end{array}$ & Cardiac arrhythmias \\
Peripheral venous & \\
thrombosis & Brain injuries \\
Secondary sepsis & Rhabdomyolysis \\
Acute pancreatitis & Acute renal failure \\
\hline
\end{tabular}

\section{STRATEGIES FOR SUCCESSFUL PREVENTION OF DKA}

DKA represents a serious metabolic derangement that requires special strategies to reduce its mortality and severe sequelae. At present, there is evidence of a wide difference between developed and developing countries in terms of mortality of patients with T1DM. In fact, in the industrialised world children unusually die of ketoacidosis, while in developing countries this emergency is common and carriers a high mortality. In sub-Saharan Africa, in particular, there are many problems regarding diabetic patients, because of the absence of an effective management system for diabetes including timely recognition of its complications and prevention.

\section{Prevention before diagnosis}

(i) Education aimed at raising the awareness of symptoms of diabetes is essential in order to prevent DKA in newly presenting TIDM (11).

(ii) Effective public awareness programmes on symptoms and signs of DKA, like information by the mass media, posters displayed in primary and secondary public schools as well as public places.

(iii) Training of healthcare workers on diagnosis of TIDM, DKA and their management.

(iv) Use of uristicks to investigate glycosuria in case of suspected diabetes.

Prevention after diagnosis

(i) For prevention of DKA in established TIDM, the primary issue should be optimal glucose control with insulin and prompt intervention in cases of metabolic decompensation.

(ii) It is essential to guarantee a dedicated diabetes care staff for children with diabetes and functional monitoring instruments.,

(iii) It is necessary to have not only regular and reliable insulin but also instruments of delivery like syringes and needles. (iv) Parents should have an appropriate health education and be effectively trained about how to manage diabetes at home especially when children get ill, in case of infections or other situations which could lead to DKA.

(v) Patients should also be trained about how to prevent DKA or recognise mild forms of DKA as soon as possible to avoid progression to severe DKA.

\section{CONCLUSION}

There may be an increase in the prevalence of TIDM in children in sub-Saharan Africa, increased awareness of presentation and knowledge of the pathophysiology and management of DKA is imperative. Several episodes of DKA can be prevented by effective public awareness programmes and education to healthcare providers. Therefore, there is an underlined need to inform both physicians and public in order to take up the challenge of reducing the incidence of DKA. Efforts at making insulin available and home monitoring of blood glucose accessible are imperative if the prevalence of DKA is to be reduced and optimise metabolic control of childhood diabetes. Collaboration of governmental and non-governmental agencies in ensuring availability of insulin and other consumables in diabetes care will also go a long way to improve the outcome of children with T1DM.

\section{AKNOWLEDGEMENTS}

To Dr. K. Muze and J. Kitundu for their comments, advice and contribution.

\section{REFERENCES}

1. Smith, C., Firth, D., Bennet, S., et al. Ketoacidosis occurring in newly diagnosed and established diabetic children. Acta Paediatr. 1998; 87: 537-541.

2. Collett-Solberg, P.F. Diabeticketoacidosis in children: review of pathophysiology and treatment with the use of the "two bags system. J. Pediatr. (Rio J). 2001; 77: 9-16.

3. Levy-Marchal, C., Patterson, C.C. and Green, A. Geographical variation of presentation at diagnosis of type 1 diabetes in children: the EURODIAB study. Diabetologia. 2001; 44: 75- 80.

4. Rewers, A., Klingensmith, G., Davis, C., et al. Diabetic ketoacidosis at onset of diabetes: The search for Diabetes in Youth Study. Diabetes. 2005; 54: 63.

5. Roche, E.F., Menon, A., Gill, D. and Hoey, H. Clinical presentation of type 1 diabetes. Pediatr. Diabetes. 2005; 6: 75-78.

6. Graves, E.J. and Gillum, B.S.1994Summary: National Hospital Discharge Survey. Advance data from vital and health statistics. National Center for Health Statistics. 1996; 278: 1-12. 
7. Vanelli, M., Chiari, G., Ghizzoni, L., et al. Effectiveness of a prevention program for diabetic ketoacidosis in children. An 8-year study in schools and private practices. Diabetes Care. 1999; 22: 7-9.

8. Swai, A.B.M., Lutale, J.L. and McLarty, D.G Prospective study of incidence of juvenile diabetes mellitus over 10 years in Dar es Salaam, Tanzania. Br. Med. J. 1993; 306: 1570-1572.

9. Elamin, A., Ghalib, M., Eltayeb, B. and Tuvemo, T. High incidence of type I diabetes mellitus in Sudanese children, 1991-1995. Ann. Saudi Med. J. 1997; 17: 478480.

10. Desta, T. Diabetic ketoacidosis in an Addis Ababa children's hospital. Ethiop. Med. J. 1992; 30: 7-11.

11. Elamin, A., Altahir, H., Ismail, B. and Tuvemo, T. Clinical pattern of childhood type 1 (insulin dependant) diabetes mellitus in Sudan. Diabetologia. 1992; 35: 645-648.

12. Monabenka, H.G., Mbika-Cardorelle, A. and Moyen, G. Ketoacidosis in children and teenagers in Congo. Sante. 2003; 13: 139-141.

13. International Insulin Foundation. The diabetes Foundation report on insulin-requiring diabetes in Sub-Saharan Africa. http://www.access2insulin. org/Diabetes Foundation Report on insulinrequiring diabetes in sub-Saharan Africa. PDF

14. Rosilio, M., Cotton, J.B., Wieliczko, M.C. et al. Factors associated with glycaemic control. A cross-sectional National wide study in 2,579 French children with type 1 diabetes. The French Pediatric Diabetes Group. Diabetes Care. 1998; 21: 1146-1153.

15. Keenan, H.T., Foster, C.M. and Bratton, S.L. Social factors associated with prolonged hospitalisation among diabetic children. Pediatrics. 2002; 109: 40-44.

16. Rwiza, H.T., Swai, A.B.M. and McLarty, D.G. Failure to diagnose diabetic ketoacidosis in Tanzania. Diabet. Med. 1986; 3: 1811-1813.

17. Elamin, A., Kheir, K.M. and Tuvemo, T. Diabetic ketoacidosis in children in Khartoum City, Sudan. East Afr. Med. J. 1994; 71: 102-105.

18. Edge,J.A., Ford-Adams, M.E. and Dunger, D.B. Causes of death in children with insulin dependant diabetes 1990-96. Arch. Dis. Child. 1999; 81: 318-323.

19. Podar, T., Solntsev, A., Reunanen, A., et al. Mortality in patients with childhood-onset type 1 diabetes in Finland, Estonia, and Lithuania: follow-up of nationwide cohorts. Diabetes Care. 2000; 23: 290-294.

20. Snorgaard, O., Eslkildsen, P.C., Vadstrup, S. and Nerup, J. Diabetic ketoacidosis in Denmark: epidemiology, incidence rates, precipitating factors and mortality rates. J. Intern. Med. 1989; 226: 223-228.

21. Dunger, D.B., Sperling, M.A., Acerin, et al. ESPE/L WPES consensus statement on diabetic ketoacidosis in children and adolescent. Arch. Dis. Child. 2004; 89: 188-194.

22. McDonnell, C.M., Pedreira, C.C., Vadamalayan, B., Cameron, F.J. and Wherther G.A. Diabetic ketoacidosis, hyperosmolarity and hypernatremia: are high-carbohydrate drinks worsening initial presentation? Pediatr. Diab. 2005; 6: 90-94.

23. Edge, J., Jakes, R., Roy, Y. et aI. The UK case-control study of cerebral oedema complicating diabetic ketoacidosis in children. Diabetologia. 2006; 49: 2002 2009.
24. Kitabatch, A.E. Low-dose insulin therapy in diabetic ketoacidosis: fact or fiction? Diabetes. Metab. Rev. 1989. 5: 337-363.

25. Della Manna, T., Steinmetz, L., Campos, P.R. et al. Subcutaneous use of fast-acting insulin analog: An alternative treatment for paediatric patients with diabetic ketoacidosis. Diabetes Care. 2005; 28: 18561861.

26. Nabarro, J.D.N., Spencer, A.G. and Stowers, J.M. Metabolic studies in severe diabetic ketoacidosis. Q. J. Med. 1952; 82: 225-248.

27. Wilson, H.K., Keuer, S.P., Lea, A.S., et al. Phosphate therapy in diabetic ketoacidosis. Arch. Intern. Med. 1982; 142: 517-520.

28. Okuda, Y., Adrogue, H.J., Field, J.B., et al. Counterproductive effects of sodium bicarbonate in diabetic ketoacidosis. J. Clin. Endocrinol. Metab. 1996; 81: 314-320.

29. Cardella, F. Insulintherapy during diabeticketoacidosis in children. Acta. Biomed. 2005; 76: 49-54.

30. Edge, J.A. and Dunger, D.B. Causes of death in children and young people with diabetes mellitus. Diabet. Med. 1997; 15: 57.

31. Lawrence, S.E., Cumming, E.A., Gaboury, I. and Daneman, D. Population-based study of incidence and risk factors for cerebral oedema in paediatric diabetic ketoacidosis. J. Pediatr. 2005; 146: 688-692.

32. Rosenbloom, A.L. Intracerebral crises during treatment of diabetic ketoacidosis. Diabetes Care. 1990; 13: 22-33.

33. Abbott, N.J.Inflammatory mediators and modulation of blood-brain barrier permeability. Cell Mol. Neurobiol. 2000; 20: 131-147.

34. Sarker, M.H. and Fraser, P.A. The role of guanylyl cyclases in the permeability response to inflammatory mediators in pial venular capillaries in the rat. J. Physiol. 2002; 540: 209-218.

35. Yang, G.Y. and Betz, A.L. Reperfusion-induced injury to the blood-brain barrier after middle cerebral artery occlusion in rats. Stroke. 1994; 25: 1658-1665.

36. Clerbaux, T., Reynaert, M., Willems, E. and Frans, A. Effect of phosphate on oxygen-hemoglobin affinity, diphosphoglycerate and blood gases during recovery from diabetic ketoacidosis. Intensive Care. Med. 1989; 15: 495-498.

37. Atchley, D., Loeb, R. and Richards, D. On Diabetic Acidosis: A detailed study of electrolyte balances following withdrawal and re-establishment of therapy. J. Clin. Invest. 1933; 12: 297-326.

38. Nabarro, J., Spencer, A. and Stowers J. Treatment of diabetic ketoacidosis. Lancet. 1952; 17: 983-989.

39. Hale, P.M., Rezvani, I., Braunstein, A.W., et al. Factors predicting cerebral edema in young children with diabetic ketoacidosis and new onset type I diabetes. Acta Paediatr. 1997; 86: 26-31.

40. Glaser, N., Barnett, P., McCaslin, L., et al. Risk factors for cerebral oedema in children with diabetic ketoacidosis. The Pediatric Emergency Medicine Collaborative Research Committee of the American Academy of Paediatrics. N. Engl. J. Med. 2001; 344: 264-269. 